\title{
THE PSYCHOSOCIAL IMPLICATIONS OF THE CLOSING OF A MINE FOR WORKERS AND THEIR FAMILIES
}

\section{Herman Strydom \& Alida Herbst}

\section{INTRODUCTION}

This article arose from a project which was launched on behalf of the Labour Union Solidarity after the interim liquidation and immediate closing of the Durban Roodepoort Deep (DRD) Gold Mine at Stilfontein. This mining community was also traumatized by an earthquake shortly before the closing of the mine. The process commenced on 27 April 2005, when a contract was drawn up with Solidarity's Helping Hand Fund to do a psychosocial situation analysis among the community. Based on the results of the psychosocial situation analysis, a project plan was submitted to Solidarity, after which a formal agreement was reached between the two parties and a meeting with the representatives of the labour union was held. Following this, the plan of action was proposed, the facilitators trained and the programme implemented. The data of the psychosocial situation analysis, the contents and course of the group sessions as well as the results that ensued from the questionnaire that was filled in by the women during the women's day as well as certain strengths present in the community are discussed. This is followed by an integrated discussion of the investigation. A number of recommendations are also made for the future.

\section{PROBLEM STATEMENT}

Unemployment and poverty are often related to social change (Alcock, 1997:37). In this case the change can be attributed to the closing of the mine for several reasons. These people can be classified as "transition poor" (Barker, 2003:333), because they find themselves in a transition phase as a result of a temporary situation. The condition of poverty and unemployment implies a condition of deprivation at the material, social and emotional levels (Alcock, 1997:3). In such aid the person should be approached in his/her entirety so that all aspects can receive attention and the reciprocal effect of the different components can be taken into account.

Although the consequences of retrenchment for the organisation have already received much attention in the literature, those affecting the victims have still not been fully investigated and described (Brockner, Wiesenfeld, Reed \& Grover, 1993). An understanding of the personal experience of retrenchment will be of interest to all organisations, exactly because it directly affects security in the workplace, the attitude towards work and the organisation involved, and the general functioning and productivity in a new workplace.

There is a strong relationship between unemployment, retrenchment and emotional problems. In such times there can also be an increase in other bio-psychosocial problems such as deterioration in physical and mental health, alcohol abuse, marital conflict, and marital and family abuse (Zastrow, 2008:368). Therefore it is clear that aid in such a situation may not only focus on one aspect of milieu in which the person lives, but on his/her total being. However, it is indeed true that the focus must initially be on the practical and most urgent problems, but afterwards the emotional and social problems must receive attention. The last-mentioned often have the most prolonged and dramatic consequences for the person and should therefore be addressed thoroughly.

This investigation is mainly based on the Family System Perspective because, firstly, it was clear to the investigation team that the individual is best understood within the context of 
relationships and, secondly, that the interaction should be assessed within a family (Corey, 2001:387). In this case the interaction was rather focused on that between man and wife within the marital relationship, although the interaction with children was also discussed. As far as possible, the focus was on the well-functioning family (Keith \& Whitaker, 1991:111-117), so that the strengths still present in the families involved could be developed further. It was realised that the immediate and practical needs of those involved should receive attention first, before the focus shifts to the emotional and social problems. Inevitably, the team was comprised mainly of social workers and the focus of the project was therefore directed at the social functioning of those involved. The following research question will be dealt with in this investigation:

- How is the possible management of such a situation investigated systematically?

- How is a plan of action developed for such a crisis situation?

- How does one direct the psychosocial management of such a situation, including individual counselling and group counselling?

- To what extent can recommendations be made for dealing with future similar situations?

\section{AIM OF THE INVESTIGATION}

The aim of this investigation is to look systematically into the situation after the closing of a mine, or a similar situation, to develop a plan of action for such a community, focusing especially on the psychosocial management of a situation such as individual and group counselling, and to make recommendations for future management of similar situations.

The following objectives can be distinguished from the aim of the investigation:

- To investigate the situation after the closing of a mine or a similar situation;

- To focus on the psychosocial management of such a situation through individual and group counselling, for instance;

- To make recommendations for future management of similar situations.

\section{CONCEPT DEFINITION}

\section{Trauma}

Barker (2003:441) sees trauma as any circumstance that affects the body or psyche negatively, for instance, shocking news or an unexpected situation that can lead to withdrawal, a sense of helplessness, depression, fear or tension. When a person receives any news that either changes or reduces everyday routines and activities, it can be experienced as traumatic, because a specific loss has to be addressed. In this case, where the mine that participants work for is provisionally liquidated, specific trauma will be experienced, such as the loss of income, loss of a normal routine and daily tasks, loss of human dignity and loss of security.

\section{LosS}

The term loss can be seen as practically synonymous with trauma, with the exception of the component deprivation. The person is deprived of something that had formed part of his/her being, or that had belonged to them. It is taken from them because of circumstances. This situation is then experienced as a life crisis (Barker, 2003:254).

\section{Crisis}

Barker (2003:103) defines crisis in two different ways, namely as an internal experience of emotional change, or a social event that holds dramatic consequences for the everyday 
functioning of the specific system. In this case of the closing of the mine, loss implies that those involved experience serious problems at all levels of their existence that influence their total vision of life and future perspective, and thus takes on crisis proportions for the community.

\section{Dismissal/retrenchment}

Barker (2003:371) defines the concept of retrenchment as follows: "Cutting back, as in reducing an agency's expenditures or services to a previous and reduced level." To be dismissed is a dramatic event and a serious source of stress and depression for both the dismissed and the one responsible for the dismissal; it can be considered as a process during which the dismissed person progresses through several phases (Ross, 2005).

\section{Poverty}

Van der Walt (2005:3) and Waters (2002:3) mention that poverty entails far more than a lack of income and means of livelihood, and that it creates the feeling of suppression, being cast out, humiliation, exclusion, dependence, helplessness and deprivation. Müller and Van Deventer (2001:88) add the following: "Poverty is therefore a human problem which dehumanises people in a dehumanising manner." Unacceptable hardship and misery therefore together form the foundation for any definition of poverty that leaves people and their next of kin socially and emotionally vulnerable and shatters all their hope for the future (Strydom, Cronjé, Roux, Strydom \& Wessels, 2005:69).

\section{RESEARCH METHODOLOGY}

The Labour Union Solidarity approached the School of Psychosocial Behavioural Sciences of the Potchefstroom Campus of North-West University to be of assistance with the psychosocial care of its members after the preliminary closing of the DRD mine at Stilfontein. After an initial orientation visit to the community involved, the researchers decided to launch a psychosocial situation analysis in the community, conduct group discussions and organise a women's day.

Since little is known about such situations as the preliminary closing of a mine and the implications of such a step, an exploratory research design (Grinnell, 2001:535) was decided on. The survey procedure (Druckman, 2005; Punch, 2003) was utilised for this study and two separate schedules were compiled - one for the male and one for the female participants, who attended the women's day. These schedules consisted of different quantitative and qualitative components (Hesse-Biber \& Leavy, 2006). The schedules were completed by means of in-depth interviewing with the men (Greeff, 2005:287; Morris, 2006:48), while the second schedule was completed by the women themselves after the conclusion of the women's day. Sampling was not an issue and everyone who approached the organisers for assistance was involved in the process.

All requirements regarding appropriate ethical issues (Grbich, 2004:88-92; Royse, 2004; Walliman, 2006:147-161) were adhered to during the investigation and especially confidentiality, anonymity and privacy were emphasised (Marlow, 2005:330). Furthermore, false assurances as well as misleading and false promises were constantly guarded against, particularly also because false rumours were being spread in the community in any case. Other aspects of ethical issues, such as voluntary and informed participation and protection against further emotional damage, were also taken into account during the investigation (Grinnell, 2001:57-68).

\section{PLANNING THE PROJECT}

In a crisis situation such as this, the inclination is to step in immediately and simply apply crisis intervention. However, the project team clearly realised that this is not a situation to be tackled 
head on, and that thorough planning was very important. Hence a working plan of action was developed with specific steps taken into consideration. Briefly, the programme entailed, firstly, a scientific psychosocial situation analysis of the total community being done to determine the feasibility of the project before the project plan could be submitted to Solidarity. Solidarity as well as the project team had compiled brochures - each in their distinct colours - that were distributed as widely as possible in the community. Following this, a meeting was arranged with representatives of Solidarity during which the plan was discussed, with a final agreement to be reached within a set period of time. Only once both parties were satisfied with the course of the project was the detailed programme planning undertaken, which included a psychosocial situation analysis in the community, a series of group work gatherings and the Women's Day. Next the facilitators were trained and the programme implemented. The outcome of the project was evaluated and possible follow-up actions were then initiated.

\section{DATA OBTAINED FROM PSYCHOSOCIAL SITUATION ANALYSIS}

The data are dealt with under the headings: identifying particulars, income sources, possibility to obtain a job, housing situation, basic means of livelihood, transport, medical situation, current state of mind and the effect of the situation on participants' behaviour.

\section{Identifying particulars}

Matters covered under identifying particulars are age, marital status, number of dependants and training.

\section{- Age}

TABLE 1

AGE OF PARTICIPANTS

\begin{tabular}{|l|c|c|}
\hline \multicolumn{1}{|c|}{ Age } & Number of participants & Percentage \\
\hline 20-29 years & 1 & $2,8 \%$ \\
\hline $30-39$ years & 6 & $16,6 \%$ \\
\hline $40-49$ years & 20 & $55,6 \%$ \\
\hline $50-59$ years & 8 & $22,2 \%$ \\
\hline 60 years and older & 1 & $2,8 \%$ \\
\hline Total & $\mathbf{3 6}$ & $\mathbf{1 0 0 , 0 0 \%}$ \\
\hline
\end{tabular}

From these data it is clear that the majority of the respondents are in the middle adulthood developmental stage, where work and employment are rated as important developmental tasks. This is confirmed by Berger (2005:564), who states that "work provides friendship, status, structure, and esteem, as well as a paycheck". The participants are in their most productive years and changes in their employment situation will severely impact on their social functioning.

\section{- Marital status}

Thirty-five participants indicated that they are married and only one that he/she is divorced.

\section{- Number of dependants}

The participants currently still have a total of 56 dependant children, of whom 39 are younger than 18 years and 17 older than 18 years. Those of the group older than 18 years are currently busy doing tertiary training, but are still dependent on their parents. In $19,4 \%$ of the families 
there are also other dependants, which include elderly parents, foster children and younger brothers or sisters.

\section{- Educational qualification}

TABLE 2

HIGHEST EDUCATIONAL QUALIFICATION

\begin{tabular}{|l|c|c|c|c|c|c|}
\hline Qualification & < Gr 10 & Gr 10 & Gr 12 & N1-N4 & Diploma & Degree \\
\hline Number of participants & 3 & 16 & 4 & 10 & 2 & 1 \\
\hline Percentage & $8,3 \%$ & $44,4 \%$ & $11,1 \%$ & $27,8 \%$ & $5,6 \%$ & $2,8 \%$ \\
\hline
\end{tabular}

The majority of the participants have worked in the mining industry for most of their lives, where a Grade 10 qualification was sufficient and further training was specifically directed to skills and knowledge required in the mining industry. This leads to most participants being doubtful about obtaining other work should they lose their current jobs.

\section{Income sources}

The vast majority, namely $23(63,9 \%)$ households, are entirely dependent on the husband's income, while $11(30,6 \%)$ of their spouses have an income and only $2(5,6 \%)$ have any additional sources of income, such as pension money. Zastrow (2008:368) points out that unemployment, or temporary unemployment, holds devastating consequences for the individual, family and community, and forces the income below the level of poverty.

\section{Possibility of obtaining another job}

In this question participants had to estimate their chances of obtaining another job on a percentage scale. Most members, namely $22(61,1 \%)$, indicated that they stand a $30 \%$ chance of obtaining another job, while only $8,3 \%$ estimated their chance at $80 \%$ and higher. Therefore most participants by far were exceptionally doubtful about their chances of obtaining another job. This attitude can also be considered realistic, because the literature (Zastrow, 2008:362) confirms that people who are only trained for a specific, narrowly defined task and then become redundant or unemployed, often do not have any marketable skills for a subsequent job.

\section{Housing situation}

Most of the members, namely 21 (58,3\%), make use of housing provided by the mine. More or less $12(33,3 \%)$ of the participants possess their own house, while the rest are dependent on rented houses. Those who use mine housing fear that they will no longer be able to live there, and those who do have their own houses indicated that they fear that they might lose the houses should they be incapable of maintaining the payment of the monthly instalment.

\section{Basic means of livelihood}

Most of the participants, namely $22(61,1 \%)$, indicated that they can, at this stage of the investigation, still provide the basic means of livelihood such as food and clothing. The rest, thus $14(38,9 \%)$, indicated that they currently do not have the necessary means of livelihood. However, this figure reflects the remarks of the participants made during the group sessions on the shortage of food and other means of livelihood. 


\section{Transport}

Most of the members, namely 34 (94,4\%), indicated that they possess their own cars. More than $70 \%$ of the latter group indicated that they will possibly have to sell the vehicle should they not be able to pay the monthly instalment.

\section{Medical situation}

Practically all the participants, $32(88,9 \%)$, belong to a medical fund provided by the mine. Because of the current circumstances at the mine, this fund is not functioning. It pays no benefits to members; therefore they are stranded with regard to medical costs. Only one participant's spouse has another medical fund. Coupled with this, it is important to point out that $24(66,7 \%)$ of the members suffer from some chronic medical condition or another which requires regular medication and treatment.

The chronic conditions that could be identified among participants include the following and are indicated as percentages in descending order. Participants could also indicate more than one health condition.

- Hypertension $16(44,4 \%)$

- High cholesterol $16(44,4 \%)$

- Diabetes $14(38,9 \%)$

- Thyroid deficiencies $12(33,3 \%)$

- Lung sicknesses (asthma, emphysema) $12(33,3 \%)$

- Back injuries $10(27,8 \%)$

- Arthritis and gout $9(25 \%)$

- $\operatorname{HIV} 3(8,3 \%)$.

From this it can be deduced that hypertension, high cholesterol and diabetes were identified as the chronic conditions that prevail most among participants. These participants were in desperate need of chronic medication and medical care at that stage.

\section{Current state of mind}

Participants could mark as many emotions on the schedule as they wished, and this is indicated as percentages in descending order.

- Uncertainty $32(88,9 \%)$

- Concern $31(86,1 \%)$

- Embarrassment $20(55,6 \%)$

- Helplessness $16(44,4 \%)$

- Anger $16(44,4 \%)$

- Hurt/wronged $16(44,4 \%)$

- Depressed $14(38,9 \%)$

- Anxious $10(27,8 \%)$

- Calm $10(27,8 \%)$

- Apathetic $2(5,6 \%)$.

From these findings it becomes evident that uncertainty and concern scored even higher than $80 \%$, which indicates that these are the emotions that practically all the people struggle with 
after such an event. Embarrassment, helplessness, anger and feelings of hurt also all scored a mark higher than 40\%. A few people also indicated that they considered suicide and even family murder, that they feel completely worn out emotionally, and experience feelings of disillusionment and worthlessness (Zastrow, 2008:368). Feelings of depression and low self-esteem also generally prevail among people in similar situations (Zastrow, 2008:368). The feelings of intense shock, disbelief and fear give rise to panic about the future, or an apathetic attitude is assumed. Since this kind of situation also brings about heartache and a mourning response (Ross, 2005), such a person must receive assistance in order to heal again.

\section{Effect of the situation on behaviour}

Participants could once again indicate as many situations as they wished. The most general behavioural changes that occurred among participants in this investigation include the following, indicated as percentages in descending order:

- High levels of irritation $27(75 \%)$

- Insomnia $19(52,8 \%)$

- Passiveness $14(38,9 \%)$

- Isolation $14(38,9 \%)$

- Do not speak $13(36,1 \%)$

- Poor appetite $9(25 \%)$

- Sleep too much and chronic exhaustion $7(19,4 \%)$.

From these responses it seems that irritation scored the highest point, namely $75 \%$. Insomnia also appeared in a high number of participants, as well as passiveness, isolation from the family and the community (Bezuidenhout, 2002:162; Zastrow, 2008:368) and silence. Other forms of behaviour that members pointed out include alcohol abuse, violence, tantrums, over-indulgence of food and general stress (Bezuidenhout, 2002:159-160).

\section{COURSE OF THE GROUP WORK SESSIONS}

At short notice the research team compiled a brochure that was distributed as widely as possible in the community, but which was specifically handed out and discussed in the groups. In this brochure the addresses, names, contact persons and contact particulars of all existing resources in the community were made available, such as churches, hospitals and welfare organisations. The types of responses to loss such as anger, bitterness, denial, need to negotiation, heartache, silence, reorganisation and adaptation were briefly dealt with, as well as possible forms of risk behaviour such as suicide, family murder, anger, feelings of fear, and loss of interest in life. The brochure also gives an indication of how to explain such events to a child. In such situations parents often steer away from talking to their children about such circumstances. Children quickly pick up the tension in the household and it is essential to give them the relevant information. Honesty towards children gives emotional security, increases insight into circumstances and decreases anxiety (Schoeman \& Van der Merwe, 2001:33-34). In this way they also become part of a positive solution to the problem.

Solidarity's Helping Hand Action made a supplementary brochure in another colour available to the community which gave additional information, amongst other things, on places they could contact for means of livelihood, financial advice, work placement, training and retraining, for instance. The action plan for the Stilfontein community was made known on the same brochure. Here special attention was given to community involvement, medical services and fund-raising. 
Because of the urgency of the situation and the need to help as many people as possible in the shortest time, group work, and specifically support groups, was decided on (Toseland \& Rivas, 2005:21). Support groups are characterised by a facilitating approach that helps members to discuss their experiences in dealing with stressful situations. The group worker helps the members in an empirical way in sharing with and helping one another (Toseland \& Rivas, 2005:23). Precisely the fact that everyone found themselves in more or less the same situation, and that group work is the context in which people can help one another, was a further motivation for adopting this approach (Becker, 2005:13; Toseland \& Rivas, 2005:17).

In general the men were self-conscious about report for assistance. Gazda, Ginter \& Horne (2001:70) mention the following in this respect: "therapy mirrors traditional female gender characteristics (more) than it does male gender characteristics." Generally men see therapy as "an unmasculine process", and they are normally less inclined to speak about their feelings than women and to acknowledge that they experience a problem (Gazda et al., 2001:70); therefore the women are important as support systems. Corey and Corey (2002:370) add that individual therapy for men is not always successful and that group work presents more opportunities for men to utilise their power and energy in their own healing process and that group work in these cases fulfils both a psycho-educational and interpersonal process-orientated role.

Initially the group meetings were planned solely for the members of Solidarity. However, a number of spouses (6) of the members also turned up as well as a few members of other labour unions (4). The four members of other labour unions live far from their families and are currently are alone and have no opportunity to attend their own support systems. The group leaders deliberated on the possible inclusion of other people than members of Solidarity and reached consensus that everyone who reported for the group sessions had to receive attention. Consequently five group sessions were presented from April to July 2005, during which 36 participants were counselled. This figure is considerably lower than was expected, but it is clear that the need for counselling is much greater. Possible reasons why people did not turn up for the group sessions can include resistance to confrontation with their own feelings, an attitude that counselling cannot change the situation, feelings of embarrassment to report for assistance, low energy levels, an apathetic attitude and general lack of motivation, and material need which is currently so high that members cannot focus on emotional and spiritual needs. For the abovementioned reasons it was important for the group workers to introduce the sessions on a personal, non-formal level and divide the problems into manageable subsections (Gazda et al., 2001:191). Statistically speaking, it can be expected that between $10 \%$ and $20 \%$ of any given population will need counselling (Centre for Human Development, 1996; Instep, 2002). From a potential population of 260 members of Solidarity, 13,8\% reported for counselling services, which thus corresponds with the mean figure.

A report form covering one page was designed on which were noted, amongst other things, the date, time and number of group members. The aim of the session, feelings, questions, concerns, the impact of the event on the family and general circumstances, as well as planning for the future, were taken into account on the form. In this way each session could be reported on and coordination of services could take place, seeing that a large number of people were involved in the project.

There were no serious forms of resistance among group members to attending the proposed group sessions. However, what was indeed noticed was a considerable amount of uncertainty and an apathetic attitude in some group members. As the group work process developed, members clearly expressed their emotions and anger, and intense concern about the future, and 
feelings of helplessness and powerlessness came to the fore. A considerable amount of emotion was displayed and some cried and spoke emotionally. It seemed as if they experienced the opportunity to unload emotionally as a positive feature, and "the positive power of group associations" (Becker, 2005:8) was once again experienced. The following discussion themes emerged largely spontaneously during the group sessions and were discussed in depth. It will be noticed that the first few themes dealt with the macro situation, while the next focused more on the intra-psychic aspects of participants and the final number of themes on the matrimonial relationship and the family.

- The implications of little to no cash flow are currently pointed out as the largest problem.

- Uncertainty about the future and the possible value of the retirement packages emerged strongly.

- Uncertainty regarding a possible next job, the compilation of Curricula Vitae and how they will be able to carry the administrative costs of work hunting also became evident. Many participants mentioned that they are only schooled for a particular task and will therefore qualify only for a limited number of other jobs.

- The fact that they do not really receive meaningful communication from mine management also emerged strongly during the group discussions.

- A considerable number of false rumours regarding the closing of the mine were spread and had a huge influence on participants' level of uncertainty.

- Bitterness towards the provincial and national government's overall non-involvement in the situation came to the fore repeatedly.

- The loss of a normal routine and the accompanying idleness frustrates most of the people.

- A feeling of worthlessness and listlessness were noticed in most of the participants, which in many cases gave lead to a feeling of desperation.

- The participants were exceptionally positive about the assistance that Solidarity and the other labour unions renders.

- A feeling of gratitude towards creditors and school headmasters regarding their obligations to pay debts and school fees was found among a considerable number of participants.

- However, they were worried about the long-term implications of debt that simply falls further and further into arrears.

- The possibility of fetching food parcels at a central point in the community is seen as too self-exposing and humiliating, and only a few people indicated that they would consider it.

- Marital conflict occurred in many cases as a result of the high levels of frustration, and tension complicated the totally negative situation even further.

- Feelings of guilt towards the family came to the fore very strongly.

- Concerns about how the situation affects the state of mind of the children were mentioned repeatedly during the group discussions, as well as the effect of an earthquake shortly before the closing of the mine on the children's behaviour and emotions.

\section{A WOMEN'S DAY}

A wide-ranging attempt was made to involve the women in the particular community and invitation cards were distributed. Posters were also put up at central spots in the community, where women could be informed about the planned occasion. Such a women's day was 
consequently arranged for a Friday and already started at 10:00 in the morning and lasted until 16:00. The women's day was attended by roughly 51 women and approximately 15 guests of the Stilfontein community. What was experienced as a weakness of the planning was the fact that child care was not provided on that day and that the presence of a few smaller children and babies was disturbing, which meant that the women could not give their full attention to the discussion at all times.

A motivational speaker was used to address the women and her message of hope served as inspiration to many, after which everyone enjoyed refreshments. The afternoon was mainly used for group work sessions and individual counselling. The participants as well as the presenters evaluated this day as being extremely meaningful, and women once again realised that it is a difficult situation for men, and that men normally react aggressively and/or apathetically to such a situation, but that their behaviour should not be seen as aimed at their wives. The discussions caused most of the women to gain insight, specific common concerns were shared and the discussions once again gave them courage for the future and a feeling of being special. They realised that they actually are the strong ones in the relationship and that their husbands and children depend and rely on them.

The women's day presented an overarching opportunity for psychosocial situation analysis and counselling. Secondly, it meant an incredible amount to the women with regard to human dignity and the opportunity to do and experience something "normal". It was a meaningful opportunity for shedding burdens, and throughout the feedback was that it was a special afternoon. Although many women expressed their uncertainty and fear, it was striking how many plans had already been made and put into effect to support their husbands, children and households. The vast majority attested that they draw endless energy from their faith. All along, positive feedback on the inputs of Solidarity was evidenced in the community. A total of 42 women filled out the questionnaires, which led to relatively reliable data on the psychosocial situation in Stilfontein. These particulars are reported and discussed briefly below.

\section{Identifying particulars}

The majority of women among the respondents, namely $17(40,5 \%)$, fell within the age group 40-49 years. This also correlates with the data gathered among the male respondents. It is evident from the data gathered that the respondents have a total of 46 children under the age of 18 years and 26 dependent children older than 18 years. A considerable number of families (12) also have other dependants for whom they care. These dependants include elderly parents, married children, family's children and even foster children. One respondent indicated that they pay part of an elderly parent's care in a home for the aged.

\section{Most general emotions that are experienced}

The women filled out this questionnaire with regard to themselves, but also indicated the emotions they observed in their husbands.

From Table 3 it is clear that concern, uncertainty, emotional hurt and anger were the most common emotional reactions of both the male and female participants. According to the literature (Bezuidenhout, 2002:162; Zastrow, 2008:368), these emotional reactions are commonly experienced by people under severe stress and may lead to risk behaviours such as substance abuse and even suicide. 
TABLE 3

EMOTIONS THAT OCCURRED IN WOMEN AND THEIR HUSBANDS

\begin{tabular}{|l|l|l|}
\hline Emotion & Husbands & Women \\
\hline Concern & $37(88,1 \%)$ & $36(85,7 \%)$ \\
\hline Uncertainty & $32(76,2 \%)$ & $34(81,0 \%)$ \\
\hline Anxiety & $20(47,6 \%)$ & $22(52,4 \%)$ \\
\hline Depression & $18(42,9 \%)$ & $20(47,6 \%)$ \\
\hline Anger & $22(52,4 \%)$ & $15(35,7 \%)$ \\
\hline Helplessness & $12(28,6 \%)$ & $14(33,3 \%)$ \\
\hline Hurt & $33(78,6 \%)$ & $13(31,0 \%)$ \\
\hline Calm & $4(9,5 \%)$ & $10(23,8 \%)$ \\
\hline Apathy & $2(4,8 \%)$ & $1(2,4 \%)$ \\
\hline Other & $2(4,8 \%)$ & $2(4,8 \%)$ \\
\hline
\end{tabular}

\section{Behaviour in reaction to the situation}

The women filled out this questionnaire with regard to themselves, but also indicated the behaviour they could observe in their husbands.

TABLE 4

FORMS OF BEHAVIOUR THAT OCCUR IN WOMEN AND THEIR HUSBANDS

\begin{tabular}{|l|c|c|}
\hline Behaviour & Husbands & Women \\
\hline Irritated & $26(62,0 \%)$ & $26(62,0 \%)$ \\
\hline Insomnia & $19(45,2 \%)$ & $17(40,5 \%)$ \\
\hline Do not talk about emotions & $13(31,0 \%)$ & $9(21,4 \%)$ \\
\hline Passiveness & $9(21,4 \%)$ & $3(7,1 \%)$ \\
\hline Sleep too much & $5(11,9 \%)$ & $5(11,9 \%)$ \\
\hline Isolation & $5(11,9 \%)$ & $5(11,9 \%)$ \\
\hline Poor appetite & $3(7,1 \%)$ & $4(9,5 \%)$ \\
\hline Other & $5(11,9 \%)$ & $5(11,9 \%)$ \\
\hline
\end{tabular}

Those who marked the "other" category were inclined to excessive exercising, over-indulgence of food, and tantrums. From Table 4 it is evident that irritation in the husbands and the women scored higher than $60 \%$. Insomnia and not talking to someone also occurred relatively often in participants. These findings correlate with the findings from the psychosocial situation analysis, where irritability was prevalent in $75 \%$ of the participants and disturbed sleep patterns could have led to even higher levels of irritability. 


\section{Behaviour observed in children}

The following is an indication of behaviour that has been observed since the temporary closing of the mine, and the responses are based on the opinions of the 42 mothers who filled in the questionnaires pertaining to this aspect.

- Aggression and fighting behaviour $22(52,4 \%)$

- Quiet and do not speak $18(42,9 \%)$

- Problems sleeping $15(35,7 \%)$

- Change in eating pattern $13(31,0 \%)$

- Isolation $13(31,0 \%)$

- Fear $11(26,2 \%)$

- Tearfulness $9(21,4 \%)$

- Problems with progress in school $7(16,7 \%)$

- Other $5(11,9 \%)$.

The few women who marked the "other" category indicated that their children have developed a fear of darkness and of being alone, and no longer wanted to be home alone since the rumours about the possible closing of the mine. The children also stopped requesting ordinary things such as snack money. It seems as if aggression, fighting behaviour and emotional withdrawal are the forms of behaviour that occurred most in children.

\section{Need for food}

Half of the respondents, namely $21(50,0 \%)$, indicated that they experience a need for food. Of the $19(45,2 \%)$ who indicated that they do not experience this need, $4(21,1 \%)$ indicated that they do already receive assistance from the emergency fund. There was also a non-response from $2(4,8 \%)$. It is uncertain how reliable these answers are, seeing that it became evident during the group discussions that a large number of respondents are simply too proud to request assistance. It seems that fresh meat is the greatest need for $6(28,6 \%)$ of the respondents, followed by fresh produce. One respondent also indicated that the food parcels are not adequate for an exceptionally large family.

Other items that were indicated include the following:

- Cleaning agents

- Personal toiletries

- Balanced food products (this respondent is pregnant and worried because her diet is inadequate)

- Specific milk formula for babies with lactose intolerance.

The following are representative of the qualitative remarks the participants made after the women's day.

- "All that helps at this stage is the labour union. We stand together and try to help one another. We rely on donations to fetch food. We are grateful, but it is difficult to stand in rows like paupers for a little food for our children."

- "It helped to talk to and encourage one another. The food aid fund that has been established fulfils the immediate need - many, many thanks. A meeting such as today to know that 
people have not forgotten about us in our circumstances is wonderful and we appreciate it immensely."

\section{Greatest concerns}

This was an open-ended question and the following remarks can be seen as representative of participants' point of view.

- Financial obligations and daily experiences 18 (42,5\%). (Here aspects are included such as day-to-day survival, paying policies, car instalments, DStv instalments, fuel and bus transport to and from school);

- Uncertainty whether their husbands will get jobs again 17 (40,5\%);

- Fears and uncertainty about the future $11(26,2 \%)$;

- Needs of children $8(19,1 \%)$;

- Housing 7 (16,7\%);

- Medical expenses 7 (16,7\%);

- Payment of municipal accounts $6(14,3 \%)$;

- Fear that their husbands will not receive retirement packages $3(7,1 \%)$;

- Inadequate diet $3(7,1 \%)$;

- High levels of tension and irritation $2(4,8 \%)$;

- Marital conflict $1(2,4 \%)$;

- Loss of control over household $1(2,4 \%)$.

From this it seems as if practical considerations such as financial obligations, day-to-day expenses, uncertainty about new work and the future scored the highest marks when concerns were discussed.

\section{Themes that emerged from the group discussions}

At times the women's day was exceptionally emotional, especially due to the message of the guest speaker. It probably led to women becoming exceptionally susceptible to communicating their fears, questions and needs. Several of the women expressed their thanks concerning the opportunity that the women's day afforded them to be able to relax, regain their human dignity for a while and find relief for their tension.

Specific discussion themes were identified, namely:

- Concern about the effect of the crisis on their husbands and children. Some of the women were genuinely uneasy about their husbands' emotional condition;

- Anger towards mine management;

- Financial constraints;

- Loss of human dignity;

- Loss of a familiar routine and lifestyle;

- Concern about the future;

- Thankfulness;

- Firm cohesion in the community;

- The role faith plays in their lives; 
- Specific practical aspects, including:

- payment of the fees for the school bus between Stilfontein and Klerksdorp;

- payment of municipal accounts;

- medical services;

- problems with transport between Stilfontein and Klerksdorp. The women recommended that a daily commuting service be initiated to increase inhabitants' mobility. Many of them have cars, but can currently not afford the fuel.

- A pregnant woman is concerned about her clothing situation - needs maternity clothing.

- A divorced woman who is unemployed and receives maintenance from her husband (a DRD employee) as part of her divorce settlement currently lives in housing provided by the mine and finds herself in dire straits, financially speaking.

- Some women expressed their concern about excessive alcohol abuse and misuse by their husbands.

- Some of the women talked about ways in which they deal with the crisis by, for instance, doing needlework for others and selling baked products to home industries, and two women even see pawnshops as their only solution.

- Several women referred to their feelings of inadequacy to support their husbands emotionally.

- Feelings of guilt and other reactions of mourning were discussed.

\section{STRENGTHS}

Because of the situation in which participants currently find themselves as a result of the possible closing of the mine, the strengths of individuals, families and the community were focused on as far as possible during the group discussions. Some of the strengths that could be identified include the following:

- Strong community support, especially from the schools, welfare organisations, churches and the broad public, amongst others;

- In general there is strong support between husbands and wives, and within the family;

- Support of the family circle and friends is also experienced as positive;

- A considerable amount of spiritual growth has also taken place in participants and they feel that their faith in God is now stronger than before. It seems that the church and caring groups enhance the meaningfulness of life for many participants;

- Specific mention is made of Solidarity's attempts to assist;

- Strong group connectedness and coherence prevails among the participants. Because everyone is involved and the community of Stilfontein mainly consists of mine workers, there is knowledge and understanding of one another's circumstances, and they help one another, although they all find themselves more or less in the same situation.

Only a few participants indicated that they receive no support and are of the opinion that pawnshops are their only hope. 


\section{DISCUSSION}

Participants are used to doing physically hard work daily and find it difficult to function without their normal routine. Furthermore, they are used to being capable of providing for their families' needs and their perception is that they have failed as breadwinners for their families and that they are worthless. The high levels of frustration and underlying depression can lead to destructive behaviour which, in this situation, can be directed at the self and the family, and can be regarded as a possible risk. It is often the women who need to be the lightning conductors in these situations and deal with the feelings of their husbands and their children. Possible risk behaviour can include matrimonial violence, family violence, and even suicide and/or family murder. Participants expressed their concern about this and eagerly wanted to know how to identify risk behaviour among their colleagues and friends. The financial emergency basically entails the loss of a meaningful cash flow to meet daily obligations. The participants also find it difficult to be dependent on food aid and experience the receipt of food parcels as exceptionally humiliating. The fact that they perceive mine management, the government and the general public as uninvolved makes them feel even more betrayed, helpless and isolated.

\section{RECOMMENDATIONS}

- It has been fully realised that the needs of all involved in such an action need to be taken into consideration, and that the physical and immediate needs must receive attention first before the focus can shift to counselling and other higher order activities.

- Since these situations normally take on crisis proportions, assistance should take place at a multidisciplinary level and this is an opportunity to let team work really develop at ground level among all the disciplines involved in the best interests of the community. Social Work, Psychology, Nursing and Theology are specifically mentioned when such a team is compiled.

- Volunteers can fulfil an important role in these situations, because there are many practical aspects that need attention. In this respect, manning the information counter, unloading and distributing the food parcels, and taking general care of the families come to mind.

- However, it is recommended that counselling, be it in individual or in group context, should be done by social workers and psychologists. Lay counsellors can cause more damage in such crisis situations than give assistance.

- The counselling sessions, be it individual or in group context, afford an opportunity to unload emotions, and mere involvement can already bring relief from negative feelings and prevent certain destructive behaviours. Such sessions are strongly advised for the future.

- Since large numbers of people are normally involved in these situations, it is only logical that the primary focus should be on the total community in order to determine the needs within the community. Following this, group work can commence and only those who are not prepared to participate in a group or those whose problems are of an extremely personal nature can then be involved in individual counselling. Group work creates the opportunity for members to identify with one another and help in dealing with one another's anxieties, and more group sessions in such situations are recommended for the future.

- An information brochure should be compiled which, amongst other things, conveys the most essential information to those involved. In this case, two brochures were compiled which contained the following information: basic and practical information such as resources in the community, which resources make provision for which type of emergency, contact numbers 
of resources, the normal responses of mourning after trauma and loss, and the subsequent high-risk behaviour that can arise from it.

- Regular communication between the labour unions and members is absolutely essential so that members know exactly what the labour unions are prepared to do in such crisis situations and what members' responsibilities entail. In this way, all kinds of false rumours that simply cause uncertainty to increase, and leave people under an erroneous impression, are nipped in the bud.

- Assistance by a financial expert regarding financial planning can be strongly recommended. In this way those involved can be guided to make realistic financial decisions. Most of the participants are desperate for cash, which can lead to their making desperate and impulsive decisions with negative long-term consequences.

- Assistance should be given in seeking alternative employment, such as making available facilities for sending and receiving faxes and for making photocopies. Compiling Curricula Vitae for a possible new job is also experienced as a huge challenge. Certain members are of the opinion that an alternative job is the only solution for them, but they are unable to afford the administrative processes in applications for work because of a lack of cash, and they also feel that they are only trained to do their current work, thus they do not stand a good chance of obtaining another job.

- Recreation opportunities for participants and their families should be encouraged, such as making available a gymnasium. Members expressed this need and it would be a good thing in terms of neutralising high levels of frustration. However, joining the gymnasium has financial implications, which once again places it beyond the reach of participants.

- Spiritual support is essential. Some participants mention that spiritual care alone cannot put cash in their pockets, but most of them did indeed indicate that this crisis affects them at the spiritual level and that they need support. Ministers and church leaders should reach those involved across denominational borders at the spiritual level. A considerable number of participants indicated that they draw a huge amount of energy from their faith, church activities and caring groups. Hence it would be helpful to give more attention to this aspect and even to organise a joint prayer occasion.

- The media can be used effectively in this process to make the public aware of the crisis in the area, which can possibly promote support for those involved.

- Information, counselling and practical assistance regarding health and obtaining medication, especially for chronic medical conditions, are essential.

- Stronger cooperation between the different interest groups who render services in the area and coordination of the existing services are extremely essential.

- Presenting a day for women during which they are exposed to motivational talks, individual discussions, group discussions and refreshments is an excellent idea and should be presented as part of such an action.

- On such a women's day provision should also be made for a child-care service so that the women can genuinely feel special and can give their full attention to the contents of the day completely detached from their normal domestic duties. 
- The needs of older children, and especially adolescents with their unique needs, should also receive attention, and group sessions can fulfil an important role here.

- A commuting service 2 to 3 times per day between Stilfontein and Klerksdorp would be helpful.

- Handing out food parcels and clothing must be handled with great care, since participants are sensitive to the situation and feel humiliated by it, in spite of their gratitude.

- Once finality has been reached about the future of the mine, a follow-up session is recommended. This would be meaningful.

\section{SUMMARY}

Although these findings do not necessarily represent the total population, they do nevertheless give an indication of the psychosocial circumstances that were prevailing in Stilfontein and can surely be generalised to any similar situation in the country. In this article, apart from the analysis of the specific situation, the aim of the investigation, concept definition and research methodology were also taken into account. The project planning, the psychosocial situation analysis with the men who were retrenched, as well as the course of the group work sessions, received attention. Following this, the women's day, arranged for the women in the community, was discussed based on the data of the questionnaire, as filled out by the women. Furthermore, certain strengths that came to the fore from the community were also discussed. A discussion of the total investigation followed, after which the focus moved to recommendations for similar situations that can occur in the future. The most important conclusion that was drawn from this was that an inclusive approach is of cardinal importance in dealing with poverty and unemployment.

\section{REFERENCES}

ALCOCK, P. 1997. Understanding poverty. Hong Kong: Macmillan.

BARKER, R.L. 2003. The social work dictionary. Washington; NASW Press.

BECKER, L. 2005. Working with groups. Cape Town: Oxford University Press.

BERGER, K.S. 2005. The developing person through the life span. New York: Worth Publishers.

BEZUIDENHOUT, F.J. 2002. A reader on selected social issues. Pretoria: Van Schaik Publishers.

BROCKNER, J., WIESENFELD, B., REED, T. \& GROVER, S. 1993. Interactive effect of job content and context on the reactions of layoff survivors. Journal of Personality and Social Psychology, 64:187-197.

CENTRE FOR HUMAN DEVELOPMENT. 1996. The leading provider of employee assistance programmes: information brochure. Pretoria: CHD.

COREY, G. 2001. Theory and practice of counselling and psychotherapy. London: Brooks/Cole Thomson Learning.

COREY, M.S. \& COREY, G. 2002. Groups: process and practice. Pacific Grove: Brooks/Cole. 
DRUCKMAN, D. 2005. Doing research: methods of inquiry for conflict analysis. London: SAGE Publications.

GAZDA, G.M., GINTER, E.J. \& HORNE, A.M. 2001. Group counseling and group psychotherapy: theory and application. Boston: Allyn and Bacon.

GRBICH, C. 2004. New approaches in social research. London: SAGE Publications.

GREEFF, M. 2005. Information collection: interviewing. In: DE VOS, A.S., STRYDOM, H., FOUCHÉ, C.B. \& DELPORT, C.S.L. (eds) Research at grass roots: for the social sciences and human service professions. Pretoria: Van Schaik Publishers: 286-313.

GRINNELL, R.M. 2001. Social work research and evaluation: quantitative and qualitative approaches. London: F.E. Peacock Publishers.

HESSE-BIBER, S.N. \& LEAVY, P. 2006. Emergent methods in social research. London: SAGE Publications.

INSTEP. 2002. What is an EAP? Available: http://www.insteplimited.com.eap.asp. [Accessed: $16 / 09 / 2002]$.

KEITH, D.V. \& WHITAKER, C.A. 1991. Experiential/symbolic family therapy. In: HORNE, A.M. \& PASSMORE, J.L. (eds) Family counseling and therapy. Itasca: F.E. Peacock Publishers: 108-140.

MARLOW, C.R. 2005. Research methods for generalist social work. London: Thomson Brooks/Cole.

MORRIS, T. 2006. Social work research methods: four alternative paradigms. London: SAGE Publications.

MÜLLER, J. \& VAN DEVENTER, W. 2001. Poverty, the poor and poor people: a practicaltheological narrative perspective. Acta Theologica, 21(2):85-99.

PUNCH, K.F. 2003. Survey research: the basics. London: SAGE Publications.

ROSS, C. 2005. The art of managing retrenchment. Available: http://www.iol.co.za/general/ news/newsprint.php?art_id=qw1025077860779C662\&sf=. [Accessed: 16/04/2007].

ROYSE, D. 2004. Research methods in social work. London: Thomson Brooks/Cole.

SCHOEMAN, J.P. \& VAN DER MERWE, M. 2001. Entering the child's world: a play therapy approach. Potchefstroom: Keurkopie.

STRYDOM, H., CRONJÉ, F.J., ROUX, A.A., STRYDOM, C. \& WESSELS, C.C. 2005. Die wisselwerking tussen MIV/VIGS en armoede: 'n psigososiale perspektief. Social Work/Maatskaplike Werk, 41(1):68-83.

TOSELAND, R.W. \& RIVAS, R.F. 2005. An introduction to group work practice. New York: Allyn and Bacon.

VAN DER WALT, J.P. 2005. Afrikaner-armoede in die 21e eeu: van verleentheid tot geleentheid. (Voordrag gelewer as deel van die Suid-Afrikaanse Akademie se kongres van 2324 Junie 2005.) Pretoria. (Ongepubliseer.)

WALLIMAN, N. 2006. Social research methods. London: SAGE Publications. 
WATERS, L.E. 2002. Psychological reactions to unemployment following retrenchment. Working Paper in Human Resource Management, Employee Relations and Organisation Studies, Number 10. Melbourne: The University of Melbourne: 1-26.

ZASTROW, C. 2008. Introduction to social work and social welfare: empowering people. New York: Thomson Brooks/Cole.

Professor Herman Strydom, Subject head, Dr Alida Herbst, Senior Lecturer, Social Work Division, School for Psychosocial Behavioural Sciences, North-West University, Potchefstroom; Subject group social work, North-West University, Potchefstroom Campus, Potchefstroom, South Africa. 